\title{
Age-Related Macular Degeneration: Pathogenesis, Genetic Background, and the Role of Nutritional Supplements
}

\author{
Marilita M. Moschos, ${ }^{1}$ Eirini Nitoda, ${ }^{2}$ \\ Irini P. Chatziralli, ${ }^{1}$ and Constantinos A. Demopoulos ${ }^{3}$ \\ ${ }^{1} 1$ st Department of Ophthalmology, Medical School, National \& Kapodistrian University of Athens, 154 Mesogion Street, \\ 11527 Athens, Greece \\ ${ }^{2} 1$ st Department of Ophthalmology, Medical School, National \& Kapodistrian University of Athens, 75 Micras Asias, \\ Goudi, 11527 Athens, Greece \\ ${ }^{3}$ Laboratory of Biochemistry, Faculty of Chemistry, National \& Kapodistrian University of Athens, 75 Micras Asias, \\ Goudi, 11527 Athens, Greece
}

Correspondence should be addressed to Marilita M. Moschos; moschosmarilita@yahoo.fr

Received 13 March 2014; Accepted 8 June 2014; Published 2 July 2014

Academic Editor: Alexander Govaris

Copyright (C) 2014 Marilita M. Moschos et al. This is an open access article distributed under the Creative Commons Attribution License, which permits unrestricted use, distribution, and reproduction in any medium, provided the original work is properly cited.

\begin{abstract}
Age-related macular degeneration (ARMD) is the leading cause of severe vision loss and blindness worldwide, mainly affecting people over 65 years old. Dry and wet ARDM are the main types of the disease, which seem to have a multifactorial background. The aim of this review is to summarize the mechanisms of ARMD pathogenesis and exhibit the role of diet and nutritional supplements in the onset and progression of the disease. Environmental factors, such as smoking, alcohol, and, diet appear to interact with mutations in nuclear and mitochondrial DNA, contributing to the pathogenesis of ARMD. Inflammatory mediators and oxidative stress, induced by the daily exposure of retina to high pressure of oxygen and light radiation, have been also associated with ARMD lesions. Other than medical and surgical therapies, nutritional supplements hold a significant role in the prevention and treatment of ARMD, eliminating the progression of macular degeneration.
\end{abstract}

\section{Introduction}

Age-related macular degeneration (ARMD) is the leading cause of severe vision loss and blindness worldwide, given that its incidence ranges from 9 to $25 \%$ at ages between 65 and 75 years, leading to blindness of over $80 \%$ of affected patients after the age of 70 years $[1,2]$. The risk of developing advanced ARMD lesions tenfolds in people over 85 years compared with those 70-74 years old [3]. ARMD is estimated to be responsible for $26 \%$ of cases of blind registration in the European Union, followed by glaucoma $(20.5 \%)$ and diabetic retinopathy (8.9\%) [1]. The beaver dam offspring study (BOSS), which was held in United States of America (USA), including 2810 subjects aged 21-84 years, revealed the incidence of early ARMD ranging from $2.4 \%$ among persons 21-34 years old to $9.8 \%$ in people over 65 years old [4]. In the same study, the incidence of early and advanced forms of
ARMD was estimated at $14.3 \%$ and $3.1 \%$, respectively, among 3917 participants from 43 to 86 years old, increasing with age [5]. The risk of developing advanced ARMD lesions on the other eye of patients who had already such lesions in one eye was determined at $43 \%$ in age-related eye disease study (AREDS) [6]. In addition, the risk of unfavorable progression of ARMD in patients who suffered from early bilateral or unilateral lesions was assessed at $26.4 \%$ and $6.3 \%$, respectively [6].

The retina is responsible for the conversion of light stimuli to neural impulses, which are transmitted to the visual cortex (occipital lobe). It consists of an outer pigmented layer (retinal pigment epithelium, RPE), which lays on Bruch membrane and an inner sensorineural layer (sensory retina), including the photoreceptors which transmit the electrical stimulus to nerve fibers layer, forming the optical nerve $[7,8]$. The macula is located in the center of the retina and 


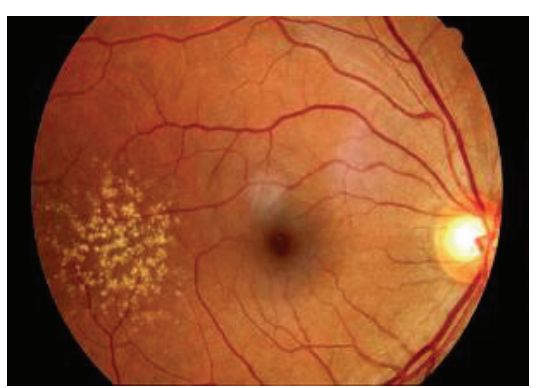

(a)

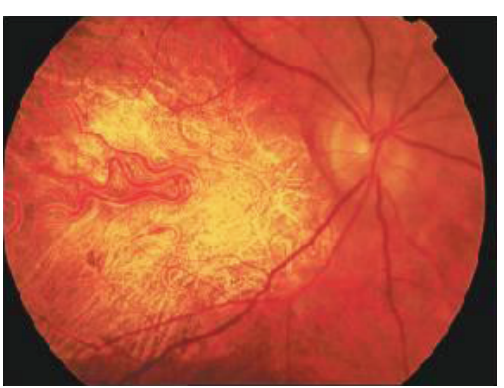

(b)

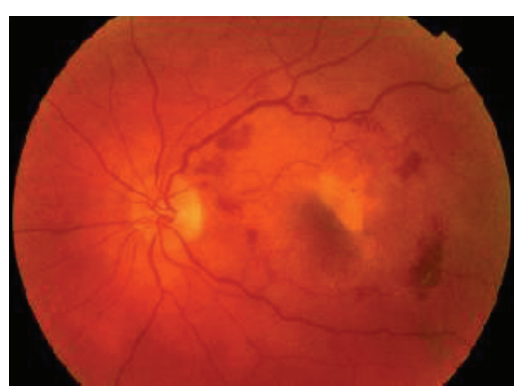

(c)

FIGURE 1: Hard drusen at the temporal side of macula in patient with dry ARMD (a), geographic atrophy (b), and CNV in patient with wet $\operatorname{ARMD}(\mathrm{c})$.

displays the highest visual acuity due to the high concentration of photoreceptors. ARMD is classified, according to the severity of the disease, into (a) mild, characterized by the presence of single soft drusen $(\geq 63 \mathrm{~mm})$, disorders of RPE, or a combination of these findings (dry ARMD) and (b) advanced, including geographic atrophy (advanced dry ARMD) and wet (exudative, neovascular) type [9]. There are no symptoms in the early stages of ARMD, but as far as the lesions are extended patients suffer from progressive visual loss, difficulty in reading and object recognition, central or paracentral scotomas, micropsia, and metamorphopsia [8].

Drusen are located between the RPE and Bruch's membrane of the macula or the peripheral retina and they mainly consist of phospholipids, triglycerides, cholesterol, cholesteryl esters, apolipoproteins, vitronectin, immunoglobulins, amyloid, and complement system components (Figure 1) [9, 10]. The atrophy of the RPE, choriocapillaris, and small vessels of the choroid are the main lesions of geographic atrophy, combined with thinning of the retina, drusen, hemorrhages, and peripapillary atrophy (Figure 1) [9]. The exudative type of ARMD is diagnosed by the presence of subretinal fluid or hemorrhage, fluid or hemorrhage beneath the RPE, accompanied with ipsilateral detachment of RPE, hard drusen, vitreous hemorrhage, a combination of the previous elements or geographic atrophy, and subretinal fibrosis (scar) in the final stages [11]. The progression of wet ARMD to choroidal neovascularization $(\mathrm{CNV})$, classic or occult, detected as a grey membrane, is followed by scar formation and leads to severe visual loss (Figure 1) [9-11].

\section{Pathogenesis of ARMD}

2.1. Environmental and Nutritional Factors. The pathogenesis of ARMD is multifactorial, related to environmental factors, genetic background, and parainflammation. Smoking is considered to be a major risk factor for the onset and the progression of ARMD, which has been positively correlated with the duration of smoking and the number of cigarettes [12]. The toxic effect of hydroquinone on retinal cells includes the accumulation of vascular endothelial growth factor (VEGF) and the decrease in macular pigment [13-15]. The levels of circulating antioxidants in smokers were found to be reduced compared with nonsmokers by $25 \%$ for ascorbic acid, alpha and beta-carotene, and cryptoxanthin and by $16 \%$ for vitamin $\mathrm{C}$, whereas vitamin $\mathrm{E}$ and carotenoids lutein, zeaxanthin, and lycopene were also decreased [16]. In addition, alcohol consumption is related to low levels of alpha-linolenic acid, which is an omega- 6 fatty acid, necessary for the synthesis of arachidonic acid and cell membranes [17]. Daily intake of more than $20 \mathrm{~g}$ of alcohol increases the risk of ARMD (odds ratio $=1.21$ ), regardless of gender [18]. The xanthophyll zeaxanthin and its isomer lutein are basic components of macular pigment, exhibiting protective role against light radiation and oxidative stress, as well as ARMD [19]. Vitamin $\mathrm{D}$ (concentrations over $38 \mathrm{nmol} / \mathrm{L}$ ) reduces the risk of ARMD by $48 \%$, due to its anti-inflammatory and antiangiogenic action and prevents the progression to the exudative form of ARMD [20]. Diet rich in cholesterol has been associated with accumulation of amyloid and induction of oxidative stress in the retina of rabbits with ARMD lesions [21].

High levels in serum of apolipoprotein B were related to inflammation and accumulation of drusen in the retina of patients suffering from wet ARMD [22]. Moreover, the consumption of red meat consists of a risk factor for the onset of early ARMD, while chicken and fatty fish (such as tuna, salmon, sardines, and herring) exhibit protective action against advanced ARMD [23, 24]. Red meat seems to be responsible for the induction of $\mathrm{N}$-nitroso elements (toxic to the retina), heme iron, and advanced glycation end products (AGEs) [23]. Patients with ARMD appear to consume less fruit, legumes, fish, shrimp, poultry, and eggs [25]. The intake of large amounts of long-chain omega-3 polyunsaturated fatty acids reduces the risk of developing ARMD, due to their antiangiogenic and neuroprotective effects [26]. However, elevated concentrations of monounsaturated fatty acids increase the risk of drusen formation and disorders of RPE [26]. High glycemic index appears to be implicated in the onset of early ARMD, while cereal and bread consumption exerts a protective effect against ARMD [27]. In addition to diet, obesity, high diastolic pressure, low glomerular filtration rate, race (high incidence of drusen in white and blacks), and ocular factors (cataract excision, hyperopia) have been also related to the onset and progression of ARMD [28-32]. Above all, ARMD is directly dependent on the age of individuals [33]. 
2.2. Genetic Background of ARMD. Single-nucleotide polymorphisms (SNPs), mutations of mitochondrial DNA (mtDNA), and micro-RNAs (mi-RNAs) consist of the genetic background of ARMD. Polymorphisms of complement factor (CF) I (CFI, chromosome 1q32), C3 complement component (chromosome 19p13), CFV, and C2 complement component (chromosome 6p21), as well as ARMS2/HTRA1 (chromosome 10q26) genes, are primarily related to the incidence of AMRD in the western world [34-56]. Zinc supplements could be used in the treatment of ARMD, taking into account that the presence of zinc in the RPE is necessary for the normal retinal function, inhibiting the action of CFH [52]. Neurodegenerative diseases, including Parkinson disease and Alzheimer, Friedrich ataxia, and amyotrophic lateral sclerosis, have been associated with polymorphisms in mtDNA [57]. Mutations in mtDNA disrupt the function of antioxidant enzymes, repair mechanisms, and chaperones, which are responsible for the folding and unfolding of macromolecules in order to obtain their functional form [58]. Polymorphisms of mtDNA, such as 4917G (MTND2* LHON4917G), T8993G, and UNG uracil-DNA glycosylase, in patients with ARMD exhibited positive correlation with the severity of the disease [58-61]. The miR-30b and miR-30d are involved in the pathogenesis of ARMD inhibiting the antioxidant catalase, while miR-155, miR-146a, and miR-146b-5p are responsible for normal function of RPE [62, 63].

2.3. Inflammatory Mediators and Oxidative Stress. The presence of any harmful agent results in activation of parainflammation, which aims at homeostasis and normal tissue function. Prolongation of parainflammation leads to oxidative stress and degenerative processes, associated with diseases such as atherosclerosis, diabetes mellitus, and ARMD [64]. Activation and accumulation of microglial cells in the retina and subretinal space, potential disruption of the blood-retinal barrier, thickening of the choroid, accompanied by deposition of macrophages and mast cell activation, and fibrosis are some of the events observed in retinal parainflammation [64]. A variety of inflammatory mediators, including aldose reductase, platelet activating factor (platelet activating factor, PAF), cytokines, such as tumor necrosis factor-alpha (TNFa), chemokines, arachidonic acid, and oxidative stress, seem to be involved in ocular diseases, including cataract, uveitis, retinal neovascularization, ARMD, and glaucoma [65-76]. Moreover, the complement system has been implicated in the pathogenesis of AMRD, as well as other neurodegenerative diseases, including Alzheimer disease and Parkinson [77]. The high pressure of oxygen in the retina, the daily exposure to the light, and the high concentration of fatty acids, including DHA (docosahexaenoic acid), favor the production of free radicals and oxidative stress [78]. The response of the immune system to oxygen free radicals and their active forms (reactive oxygen species, ROS) is called oxidative stress and is thought to participate in both aging process and ocular diseases, including keratitis, uveitis, cataract, retinopathy of prematurity, and ARMD [79].

Studies in aged RPE revealed high levels of VEGF and interleukins (IL) 12 and 10, although both of these interleukins exhibit inverse effect, since the former promotes the production of interferon gamma, TNF-a, and T-lymphocytes, while the latter inhibits inflammatory mediators [80]. Reduced concentrations of proinflammatory cytokines, such as IL-8, IL-15, IL-6, granulocyte macrophage colony-stimulating factor (GM-CSF), and stromal cellderived factor (SDF-1a), were defined in aged RPE [80]. The expression of chemokines receptors CCR1 and CCR2 in CD14+ CD16+ monocytes appeared to be increased by 3.5 and 2.2 times, respectively, in patients with neovascular ARMD [81]. Peroxisome proliferator-activated receptors (PPARs) are implicated in the pathogenesis of ARMD, as well as other diseases, including obesity, diabetes mellitus, atherosclerosis, cancer, and neurodegenerative disorders [82]. PPARs-gamma are expressed in the RPE and vascular endothelial cells of choroid, inhibiting VEGF and endothelin1 and inducing the plasminogen activator inhibitor-1 [82]. Furthermore, PPARs-gamma increase the expression of antioxidant enzymes and suspend proinflammatory factors and metalloproteinase (matrix metalloproteinase, MMP) 9, which degrades the extracellular matrix components. The hypoxia-inducible factors (HIFs) 1 and 2 (HIF-1, HIF-2) appear to be involved in the formation of neovascular membranes in exudative form of the disease, increasing VEGF [83].

Although lipofuscin is normally found in retinal epithelium, extremely elevated concentrations of this pigment have been associated with cell damage, induced by the formation of CEP proteins (carboxyethylpyrrole proteins) and bisretinoids oxidation [78]. Bis-retinoids are responsible for parainflammation and the accumulation of AGEs [78]. Iron accumulation in RPE is a major cause of increased lipofuscin, degeneration of RPE, and subretinal neovascularization [84]. Amyloid (component of drusen) favors the expression of VEGF by interfering at the level of mRNA and proteins and suppresses pigment epithelium-derived factor (PEDF), which prevents angiogenesis [85]. The endocytosis of A2E (basic component of lipofuscin) and other components, including amyloid-beta, crystals of uric acid, and cholesterol, leads to destruction of lysosomes and activation of inflammasome NLRP3, which appears to affect the release of IL-1b from $\mathrm{A} 2 \mathrm{E}$ [86]. The A2E affects the interaction of cytochrome c and cytochrome oxidase (COX), promoting the detachment of cytochrome $\mathrm{c}$ from the inner mitochondrial membrane, followed by oxidative stress and insufficient production of ATP [87]. The anatomical and functional impairment of mitochondrial, which has been observed in patients with ARMD, seems to be associated with reduced energy, impaired apoptosis, ROS accumulation, and elimination of superoxide dismutase 2 (SOD2), leading to degeneration of RPE, shortening and thickening of Bruch's membrane, and degeneration of photoreceptors [88].

PAF (1-0-alkyl-2-acetyl-sn-glycero-3-phosphocholine) is a low molecular weight phospholipid, regulated by PAF acetylhydrolases (PAF-AHs), a group of phospholipases being responsible for hydrolysis and deactivation of PAF in blood and tissues, as well as by its receptor (PAF-R, flt-1), which is a transmembrane G-protein, being expressed in a wide range of cells (RPE cells, monocytes, lymphocytes, vascular 
endothelial and smooth muscle cells, and keratinocytes) [8993]. A variety of physiological processes, including platelet adhesion, activation of neutrophils and macrophages, calcium metabolism, pregnancy, implantation of the ovum, and ovulation, have been associated with PAF stimulation, which can, also, raise mechanisms involved in acute inflammation, asthma, systemic or cardiac anaphylaxis, infectious shock, and thrombosis [89-92].

Allergic conjunctivitis has been related to release of histamine and serotonin, vasodilation, increased vascular permeability and accumulation and degranulation of eosinophils, and neutrophils, caused by the ocular action of PAF [94-96]. Furthermore, PAF is involved in the healing of corneal epithelium, apoptosis of keratocytes and myofibroblasts, and binding of epithelial cells with the basement membrane, stimulating selective MMPs, serine proteases, transcription factors, and apoptotic agents [9799]. PAF-induced corneal neovascularization takes place by the stimulation of arachidonic acid, lipid hydroperoxides, and the expression of VEGF in endothelial cells, as well as the migration of vascular endothelial cells, whereas PAF inhibits the antiangiogenic thrombospondin 1 (TSP-1) [100, 101]. Oxidative stress and free radicals, being involved in pathogenesis of ischemic retinopathies, such as retinal vein occlusion and diabetic retinopathy, are the stimuli for the release and activation of PAF [102]. PAF interacts with P-selectins of retinal and choroidal vascular endothelium, inducing endothelial damage and vascular thrombosis [103]. The migration of leukocytes to vascular endothelium and its subsequent disruption, the activation of phospholipases and proteases, and the disturbance of permeability of mitochondrial pores are implicated in the cytotoxic effect of PAF in retinal vascular endothelial cells [104-107].

\section{Treatment of ARMD and Nutritional Supplements}

3.1. Medical and Surgical Therapies in ARMD. Food supplements appear to be the basic therapy of dry ARMD, whereas exudative form is treated with the use of antiVEGF and anti-inflammatory agents, as well as laser (laser photocoagulation or photodynamic therapy). Ranibizumab (Lucentis; Genentech, South San Francisco, CA/Roche, Basel, Switzerland, 2006), bevacizumab (Avastin; Genentech, South San Francisco, CA/Roche, Basel, Switzerland, 2005), pegaptanib sodium (Macugen; Eyetech Inc., Palm Beach Gardens, FL, 2004), and VEGF trap or Aflibercept (EYLEA; Regeneron Pharmaceutical Inc. and Bayer, Tarrytown, NY, 2011) are the major anti-VEGF agents used in treatment of wet ARMD [108]. The therapeutic effects of these agents include improvement of visual acuity, as well as decrease of subretinal or intraretinal fluid, central macular thickness, and neovascularization [109-113]. The most common complications of intravitreal injections of anti-VEGF include intraocular inflammation and increased intraocular pressure, whereas hypertension, thromboembolic (acute myocardial infarction, vascular incident), and hemorrhagic episodes are some of the systemic complications observed in low incidence
$[114,115]$. The need for repeated injections and the inflammatory effect of photodynamic therapy (transient vascular occlusion, retinal and choroidal ischemia) led to the combination of anti-VEGF agents with steroids (such as triamcinolone) or photodynamic therapy [116]. Surgical treatment is applied on the complications of ARMD, including epiretinal membrane formation, subretinal hemorrhage, and retinal pigment epithelium detachment (PED), while transplantation of RPE cell is a new challenge in the treatment of ARMD.

3.2. The Role of Nutritional Supplements. AREDS study, conducted with 4757 participants aged 55-80 years, revealed that the daily intake of zinc ( $80 \mathrm{mg})$, copper ( $2 \mathrm{mg})$, and antioxidants (vitamin C: $500 \mathrm{mg}$, vitamin E: 400 IU, beta-carotene: $15 \mathrm{mg}$ ) reduces the risk of advanced ARMD lesions (OR: 0.75 and decrease of relative risk (RR) by $21 \%$ for an individual taking zinc, OR: 0.80 and $\mathrm{RR}$ reduction by $17 \%$ for individuals taking antioxidant components), preventing visual loss (OR: 0.72 and RR reduction by 25\%) [117]. However, nutritional supplements should be used with caution, taking into account previous studies, which have related the intake of vitamin A and beta-carotene to increased incidence of cardiovascular diseases and lung cancer, especially in smokers and workers who have been exposed to asbestos [118, 119]. Supplements containing lutein, zeaxanthin, and DHA improve pigment concentrations in macula, providing extra protection against phototoxicity and oxidative stress [120, 121]. Folic acid and vitamins B6 and B12 appear to reduce homocysteine, which promotes, at high levels, dysfunction of vascular endothelium and development of ARMD lesions [122]. Overall, patients should include in their diet fruits, legumes, and fatty fishes, eliminating red meat, alcohol, and smoking, as it has been already mentioned.

The effect of vitamin supplements on the action and metabolism of PAF was recently investigated in rabbit's platelets and leucocytes. All supplements, including InShape (Farmex), Nutrof (Thea), Ocuvite (Bausch and Lomb), and Vitalux (Novartis), appeared to inhibit, even in low dose, the aggregation of platelets, which is closely related to the action of PAF [123]. The inhibitory action of these supplements was similar to that of potent PAF receptor antagonists, such as WEB2170, BN52021, and Rupatadine [123]. Particularly, Nutrof was the most potent inhibitor of PAF-induced aggregation, while Vitalux was the weaker one [123]. The implication of vitamin supplements in metabolism of PAF was determined by the levels of PAF-AHs, as well as PAF-cholinephosphotransferase (PAF-CPT) and lyso-PAFacetyltransferase (lyso-PAF-AT) enzymatic activities (these enzymes catalyze the synthesis of PAF). The strongest suppression of PAF synthesis was achieved by Vitalux, through the elimination of PAF-CPT and lyso-PAF-AT levels, indicating significant anti-inflammatory activity [123]. On the other hand, Nutrof increased PAF-AHs activity more than the other supplements, exhibiting high antiangiogenic properties, but it had no effect on PAF synthesis and inflammatory process [123]. Ocuvite slightly increased PAF-AHs levels, as Vitalux did, but it had no anti-inflammatory properties [123]. Finally, 
InShape seemed to have no interference in angiogenesis but a minor one in the inflammatory action of PAF [123].

\section{Conclusion}

The multifactorial background of ARMD complicates the treatment of the disease and generates the need for continuous research in ARMD therapy, taking into account that $80 \%$ of affected patients are blind after the age of 70 years. Numerous studies have highlighted the role of diet and vitamin supplements in inhibiting parainflammation and oxidative stress, which are involved in pathogenesis of ARMD. Changing dietary habits and eliminating smoking and alcohol could prevent the onset and the progression of ARMD, protecting the patients from vision loss and blindness.

\section{Conflict of Interests}

The authors declare that there is no conflict of interests regarding the publication of this paper. The authors alone are responsible for the content and writing of the paper.

\section{References}

[1] E. Prokofyeva and E. Zrenner, "Epidemiology of major eye diseases leading to blindness in Europe: a literature review," Ophthalmic Research, vol. 47, no. 4, pp. 171-188, 2012.

[2] J. J. Wang, S. Foran, and P. Mitchell, "Age-specific prevalence and causes of bilateral and unilateral visual impairment in older Australians: the Blue Mountains Eye Study," Clinical and Experimental Ophthalmology, vol. 28, no. 4, pp. 268-273, 2000.

[3] F. Jonasson, A. Arnarsson, G. Eirksdottir et al., "Prevalence of age-related macular degeneration in old persons: age, gene/environment susceptibility Reykjavik study," Ophthalmology, vol. 118, no. 5, pp. 825-830, 2011.

[4] R. Klein, K. J. Cruickshanks, S. D. Nash et al., "The prevalence of age-related macular degeneration and associated risk factors," Archives of Ophthalmology, vol. 128, no. 6, pp. 750-758, 2010.

[5] R. Klein, B. E. Klein, M. D. Knudtson, S. M. Meuer, M. Swift, and R. E. Gangnon, "Fifteen-year cumulative incidence of age-related macular degeneration: the beaver dam eye study," Ophthalmology, vol. 114, no. 2, pp. 253-262, 2007.

[6] N. M. Bressler, S. B. Bressler, N. G. Congdon et al., "Potential public health impact of Age-Related Eye Disease Study results: AREDS report no. 11," Archives of Ophthalmology, vol. 121, no. 11, pp. 1621-1624, 2003.

[7] R. S. Snell and M. A. Lemp, “The eyeball," in Clinical Anatomy of the Eye, pp. 189-206, Blackwell Science, Malden, Mass, USA, 1997.

[8] T. M. Johnson and M. W. Johnson, "Macular diseases," in Clinical Retina, D. A. Quillen and B. A. Blodi, Eds., American Medical Association Press, Chicago, Ill, USA, 2002.

[9] JI. Lim, Age-Related Macular Degeneration, Informa Healthcare, New York, NY, USA, 2008.

[10] S. W. Cousins, G. C. Karl, and D. G. Espinosa-Heidmann, "Clinical strategies for diagnosis and treatment of ARMD: implications from research," in Macular Degeneration, P. L. Penfold and J. M. Provis, Eds., pp. 167-200, Springer, New York, NY, USA, 2005.
[11] J. Jonisch and G. Shah, "Diagnosis of age-related macular degeneration," in Age-Related Macular Degeneration: Diagnosis and Treatment, A. C. Ho and C. D. Regillo, Eds., Springer Science+Business Media, New York, NY, USA, 2011.

[12] J. C. Khan, D. A. Thurlby, H. Shahid et al., "Smoking and age related macular degeneration: the number of pack years of cigarette smoking is a major determinant of risk for both geographic atrophy and choroidal neovascularisation," British Journal of Ophthalmology, vol. 90, no. 1, pp. 75-80, 2006.

[13] M. Pons and M. E. Marin-Castaño, "Cigarette smoke-related hydroquinone dysregulates MCP-1, VEGF and PEDF expression in retinal pigment epithelium in vitro and in vivo," PLOS ONE, vol. 6, no. 2, Article ID e16722, 2011.

[14] M. Pons and M. E. Marin-Castaño, "Nicotine increases the VEGF/PEDF ratio in retinal pigment Epithelium: a possible mechanism for $\mathrm{CNV}$ in passive smokers with AMD," Investigative Ophthalmology and Visual Science, vol. 52, no. 6, pp. 38423853, 2011.

[15] B. R. J. Hammond, B. R. Wooten, and D. M. Snodderly, "Cigarette smoking and retinal carotenoids: implications for age-related macular degeneration," Vision Research, vol. 36, no. 18, pp. 3003-3009, 1996.

[16] A. J. Alberg, "The influence of cigarette smoking on circulating concentrations of antioxidant micronutrients," Toxicology, vol. 180, no. 2, pp. 121-137, 2002.

[17] E. D. O'Connell, J. M. Nolan, J. Stack et al., "Diet and risk factors for age-related maculopathy," The American Journal of Clinical Nutrition, vol. 87, no. 3, pp. 712-722, 2008.

[18] M. K. Adams, E. W. Chong, E. Williamson et al., "20/20Alcohol and age-related macular degeneration: the Melbourne Collaborative Cohort Study," The American Journal of Epidemiology, vol. 176, no. 4, pp. 289-298, 2012.

[19] C. Delcourt, I. Carrière, M. Delage et al., "Plasma lutein and zeaxanthin and other carotenoids as modifiable risk factors for age-related maculopathy and cataract: the POLA study," Investigative Ophthalmology and Visual Science, vol. 47, no. 6, pp. 2329-2335, 2006.

[20] A. E. Millen, R. Voland, S. A. Sondel et al., "Vitamin D status and early age-related macular degeneration in postmenopausal women," Archives of Ophthalmology, vol. 129, no. 4, pp. 481-489, 2011.

[21] B. Dasari, J. R. Prasanthi, G. Marwarha, B. B. Singh, and O. Ghribi, "Cholesterol-enriched diet causes age-related macular degeneration-like pathology in rabbit retina," BMC Ophthalmology, vol. 11, no. 1, article 22, 2011.

[22] S. Fauser, D. Smailhodzic, A. Caramoy et al., "Evaluation of serum lipid concentrations and genetic variants at high-density lipoprotein metabolism loci and TIMP3 in age-related macular degeneration," Investigative Ophthalmology and Visual Science, vol. 52, no. 8, pp. 5525-5528, 2011.

[23] E. W. Chong, J. A. Simpson, L. D. Robman et al., "Red meat and chicken consumption and its association with age-related macular degeneration," The American Journal of Epidemiology, vol. 169, no. 7, pp. 867-876, 2009.

[24] C. Augood, U. Chakravarthy, I. Young et al., "Oily fish consumption, dietary docosahexaenoic acid and eicosapentaenoic acid intakes, and associations with neovascular age-related macular degeneration," The American Journal of Clinical Nutrition, vol. 88, no. 2, pp. 398-406, 2008.

[25] L. Jia, X. Shen, R. Fan et al., "Risk factors for age-related macular degeneration in elderly Chinese opulation in Shenyang 
of China," Biomedical and Environmental Sciences, vol. 24, no. 5, pp. 506-511, 2011.

[26] B. Merle, M. Delyfer, J. Korobelnik et al., "Dietary omega-3 fatty acids and the risk for age-related maculopathy: the alienor study," Investigative Ophthalmology and Visual Science, vol. 52, no. 8, pp. 6004-6011, 2011.

[27] S. Kaushik, J. J. Wang, V. Flood et al., "Dietary glycemic index and the risk of age-related macular degeneration," The American Journal of Clinical Nutrition, vol. 88, no. 4, pp. 1104-1110, 2008.

[28] S. Fraser-Bell, J. Wu, R. Klein et al., "Cardiovascular risk factors and age-related macular degeneration: the Los Angeles Latino Eye Study," The American Journal of Ophthalmology, vol. 145, no. 2, pp. 308-316, 2008.

[29] D. E. Weiner, H. Tighiouart, R. Reynolds, and J. M. Seddon, "Kidney function, albuminuria and age-related macular degeneration in NHANES III," Nephrology, Dialysis, Transplantation, vol. 26, no. 10, pp. 3159-3165, 2011.

[30] Y. Oshima, T. Ishibashi, T. Murata, Y. Tahara, Y. Kiyohara, and T. Kubota, "Prevalence of age related maculopathy in a representative Japanese population: the Hisayama study," British Journal of Ophthalmology, vol. 85, no. 10, pp. 1153-1157, 2001.

[31] L. Ho, S. S. Boekhoorn, C. M. Van Duijn et al., "Cataract surgery and the risk of aging macula disorder: the Rotterdam study," Investigative Ophthalmology and Visual Science, vol. 49, no. 11, pp. 4795-4800, 2008.

[32] W. Xu, J. E. Grunwald, T. I. Metelitsina et al., "Association of risk factors for choroidal neovascularization in age-related macular degeneration with decreased foveolar choroidal circulation," The American Journal of Ophthalmology, vol. 150, no. 1, pp. 40.e2-47.e2, 2010.

[33] A. L. Butt, E. T. Lee, R. Klein et al., "Prevalence and risks factors of age-related macular degeneration in Oklahoma Indians: the vision keepers study," Ophthalmology, vol. 118, no. 7, pp. 13801385, 2011.

[34] P. Sundaresan, P. Vashist, R. D. Ravindran et al., "Polymorphisms in ARMS2/HTRA1 and complement genes and agerelated macular degeneration in India: findings from the INDEYE study," Investigative Ophthalmology and Visual Science, vol. 53, no. 12, pp. 7492-7497, 2012.

[35] A. Farwick, B. Dasch, B. H. F. Weber, D. Pauleikhoff, M. Stoll, and H.-W. Hense, "Variations in five genes and the severity of age-related macular degeneration: results from the Muenster aging and retina study," Eye, vol. 23, no. 12, pp. 2238-2244, 2009.

[36] A. Farwick, J. Wellmann, M. Stoll, D. Pauleikhoff, and H. Hense, "Susceptibility genes and progression in age-related maculopathy: a study of single eyes," Investigative Ophthalmology \& Visual Science, vol. 51, no. 2, pp. 731-736, 2010.

[37] L. G. Fritsche, T. Loenhardt, A. Janssen et al., "Age-related macular degeneration is associated with an unstable ARMS2 (LOC387715) mRNA," Nature Genetics, vol. 40, no. 7, pp. 892896, 2008.

[38] M. T. Andreoli, M. A. Morrison, B. J. Kim et al., "Comprehensive analysis of complement factor $\mathrm{H}$ and LOC387715/ARMS2/HTRA1 variants with respect to phenotype in advanced age-related macular degeneration," The American Journal of Ophthalmology, vol. 148, no. 6, pp. 869-874, 2009.

[39] Y. Tong, J. Liao, Y. Zhang, J. Zhou, H. Zhang, and M. Mao, "LOC387715/HTRA1 gene polymorphisms and susceptibility to agerelated macular degeneration: a huge review and metaanalysis," Molecular Vision, vol. 16, pp. 1958-1981, 2010.

[40] H. Bessho, S. Honda, N. Kondo, and A. Negi, "The association of age-related maculopathy susceptibility 2 polymorphisms with phenotype in typical neovascular Age-related macular degeneration and polypoidal choroidal vasculopathy," Molecular Vision, vol. 17, pp. 977-982, 2011.

[41] Y. Cheng, L. Huang, X. Li, P. Zhou, W. Zeng, and C. Zhang, "Genetic and functional dissection of ARMS2 in age-related macular degeneration and polypoidal choroidal vasculopathy," PLoS ONE, vol. 8, no. 1, Article ID e53665, 2013.

[42] A. E. Hughes, G. M. Mullan, and D. T. Bradley, "Complement factor B polymorphism $32 \mathrm{~W}$ protects against agerelated macular degeneration," Molecular Vision, vol. 17, pp. 983-988, 2011.

[43] J. Tian, W. Yu, X. Qin et al., "Association of genetic polymorphisms and age-related macular degeneration in Chinese population," Investigative Ophthalmology and Visual Science, vol. 53, no. 7, pp. 4262-4269, 2012.

[44] L. Wu, Q. Tao, W. Chen et al., "Association between polymorphisms of complement pathway genes and age-related macular degeneration in a Chinese population," Investigative Ophthalmology \& Visual Science, vol. 54, no. 1, pp. 170-174, 2013.

[45] B. Buentello-Volante, G. Rodriguez-Ruiz, A. Miranda-Duarte et al., "Susceptibility to advanced age-related macular degeneration and alleles of complement factor $\mathrm{H}$, complement factor $\mathrm{B}$, complement component 2, complement component 3, and age-related maculopathy susceptibility 2 genes in a Mexican population," Molecular Vision, vol. 18, pp. 2518-2525, 2012.

[46] M. Heurich, R. Martínez-Barricarte, N. J. Francis et al., "Common polymorphisms in $\mathrm{C} 3$, factor $\mathrm{B}$, and factor $\mathrm{H}$ collaborate to determine systemic complement activity and disease risk," Proceedings of the National Academy of Sciences, vol. 108, no. 21, pp. 8761-8766, 2011.

[47] C. Delcourt, M. Delyfer, M. Rougier et al., "Associations of complement factor $\mathrm{H}$ and smoking with early age-related macular degeneration: the ALIENOR study," Investigative Ophthalmology and Visual Science, vol. 52, no. 8, pp. 5955-5962, 2011.

[48] C. Xing, T. A. Sivakumaran, J. J. Wang et al., "Complement factor $\mathrm{H}$ polymorphisms, renal phenotypes and age-related macular degeneration: the blue mountains eye study," Genes and Immunity, vol. 9, no. 3, pp. 231-239, 2008.

[49] D. D. G. Despriet, C. C. W. Klaver, J. C. M. Witteman et al., "Complement factor $\mathrm{H}$ polymorphism, complement activators, and risk of age-related macular degeneration," The Journal of the American Medical Association, vol. 296, no. 3, pp. 301-309, 2006.

[50] P. X. Shaw, L. Zhang, M. Zhang et al., "Complement factor $\mathrm{H}$ genotypes impact risk of age-related macular degeneration by interaction with oxidized phospholipids," Proceedings of the National Academy of Sciences of the United States of America, vol. 109, no. 34, pp. 13757-13762, 2012.

[51] A. S. Silva, A. G. Teixeira, L. Bavia et al., "Plasma levels of complement proteins from the alternative pathway in patients with age-related macular degeneration are independent of Complement Factor $\mathrm{H}$ Tyr ${ }^{402}$ His polymorphism," Molecular Vision, vol. 18, pp. 2288-2299, 2012.

[52] R. Nan, I. Farabella, F. F. Schumacher et al., "Zinc binding to the Tyr402 and His402 allotypes of complement factor H: possible implications for age-related macular degeneration," Journal of Molecular Biology, vol. 408, no. 4, pp. 714-735, 2011.

[53] R. E. Gangnon, K. E. Lee, B. E. K. Klein, S. K. Iyengar, T. A. Sivakumaran, and R. Klein, "Effect of the $\mathrm{Y} 402 \mathrm{H}$ variant in the complement factor $\mathrm{H}$ gene on the incidence and progression of age-related macular degeneration: results from multistate models applied to the beaver dam eye study," Archives of Ophthalmology, vol. 130, no. 9, pp. 1169-1176, 2012. 
[54] F. Simonelli, G. Frisso, F. Testa et al., "Polymorphism p.402Y >H in the complement factor $\mathrm{H}$ protein is a risk factor for age related macular degeneration in an Italian population," British Journal of Ophthalmology, vol. 90, no. 9, pp. 1142-1145, 2006.

[55] R. Martínez-Barricarte, S. Recalde, P. Fernández-Robredo et al., "Relevance of complement factor H-related 1 (CFHR1) genotypes in age-related macular degeneration," Investigative Ophthalmology \& Visual Science, vol. 53, no. 3, pp. 1087-1094, 2012.

[56] A. Thakkinstian, M. McEvoy, U. Chakravarthy et al., "The association between complement component 2/complement factor B polymorphisms and age-related macular degeneration: a HuGE review and meta-analysis," The American Journal of Epidemiology, vol. 176, no. 5, pp. 361-372, 2012.

[57] J. M. van der Walt, K. K. Nicodemus, E. R. Martin et al., "Mitochondrial polymorphisms significantly reduce the risk of Parkinson disease," The American Journal of Human Genetics, vol. 72, no. 4, pp. 804-811, 2003.

[58] H. Lin, H. Xu, F. Liang et al., "Mitochondrial DNA damage and repair in rpe associated with aging and age-related macular degeneration," Investigative Ophthalmology and Visual Science, vol. 52, no. 6, pp. 3521-3529, 2011.

[59] C. Vives-Bauza, M. Anand, A. K. Shirazi et al., "The age lipid A2E and mitochondrial dysfunction synergistically impair phagocytosis by retinal pigment epithelial cells," Journal of Biological Chemistry, vol. 283, no. 36, pp. 24770-24780, 2008.

[60] J. A. Canter, L. M. Olson, K. Spencer et al., "Mitochondrial DNA polymorphism A4917G is independently associated with agerelated macular degeneration," PLoS ONE, vol. 3, no. 5, article e2091, 2008.

[61] J. Blasiak, E. Synowiec, A. Salminen, and K. Kaarniranta, "Genetic variability in DNA repair proteins in age-related macular degeneration," International Journal of Molecular Sciences, vol. 13, no. 10, pp. 13378-13397, 2012.

[62] R. Haque, E. Chun, J. C. Howell, T. Sengupta, D. Chen, and H. Kim, "MicroRNA-30b-mediated regulation of catalase expression in human ARPE-19 cells," PLoS ONE, vol. 7, no. 8, Article ID e42542, 2012.

[63] W. J. Lukiw, B. Surjyadipta, P. Dua, and P. N. Alexandrov, "Common micro RNAs (miRNAs) target complement factor $\mathrm{H}(\mathrm{CFH})$ regulation in Alzheimer's disease $(\mathrm{AD})$ and in agerelated macular degeneration (AMD)," International Journal of Biochemistry and Molecular Biology, vol. 3, no. 1, pp. 105-116, 2012.

[64] S. M. Whitcup, A. Sodhi, J. P. Atkinson et al., "The role of the immune response in age-related macular degeneration," International Journal of Inflammation, vol. 2013, Article ID 348092, 10 pages, 2013.

[65] U. C. S. Yadav, S. K. Srivastava, and K. V. Ramana, "Understanding the role of aldose reductase in ocular inflammation," Current Molecular Medicine, vol. 10, no. 6, pp. 540-549, 2010.

[66] J. Vane and R. Botting, "Inflammation and the mechanism of action of anti-inflammatory drugs," The FASEB Journal, vol. 1, no. 2, pp. 89-96, 1987.

[67] A. M. Irani, "Ocular mast cells and mediators," Immunology and Allergy Clinics of North America, vol. 28, no. 1, pp. 25-42, 2008.

[68] A. Leonardi, L. Motterle, and M. Bortolotti, "Allergy and the eye," Clinical and Experimental Immunology, vol. 153, supplement 1, pp. 17-21, 2008.
[69] K. V. Ramana, "Tumor necrosis factor-alpha converting enzyme: implications for ocular inflammatory diseases," International Journal of Biochemistry and Cell Biology, vol. 42, no. 7, pp. 1076-1079, 2010.

[70] R. Maleshiński, M. Mrugacz, and A. Bakunowicz-Łazarczyk, "The role of chemokines in ocular diseases. Part II. Participation of chemokines in ocular diseases," Klinika Oczna, vol. 109, no. 7-9, pp. 345-348, 2007.

[71] G. R. Wallace, S. John Curnow, K. Wloka, M. Salmon, and P. I. Murray, "The role of chemokines and their receptors in ocular disease," Progress in Retinal and Eye Research, vol. 23, no. 4, pp. 435-448, 2004.

[72] P. Bhattacherjee, "The role of arachidonate metabolites in ocular inflammation," Progress in Clinical and Biological Research, vol. 312, pp. 211-227, 1989.

[73] D. Wakefield and A. Lloyd, "The role of cytokines in the pathogenesis of inflammatory eye disease," Cytokine, vol. 4, no. 1, pp. 1-5, 1992.

[74] N. S. Bora, P. Jha, and P. S. Bora, "The role of complement in ocular pathology," Seminars in Immunopathology, vol. 30, no. 2, pp. 85-95, 2008.

[75] M. P. Davey and J. T. Rosenbaum, "The human leukocyte antigen complex and chronic ocular inflammatory disorders," The American Journal of Ophthalmology, vol. 129, no. 2, pp. 235243, 2000.

[76] O. Raby, A. Salvanet-Bouccara, and F. Forestier, "The eye and chronic inflammatory diseases of the intestines. Immunopathological and genetic aspects. Apropos of 3 cases," Journal Français d'Ophtalmologie, vol. 10, no. 11, pp. 683-698, 1987.

[77] B. Liu, L. Wei, C. Meyerle et al., "Complement component C5a promotes expression of IL-22 and IL-17 from human T cells and its implication in age-related macular degeneration," Journal of Translational Medicine, vol. 9, no. 1, article 111, pp. 1-12, 2011.

[78] J. Z. Nowak, “Oxidative stress, polyunsaturated fatty acidsderived oxidation products and bisretinoids as potential inducers of CNS diseases: focus on age-related macular degeneration," Pharmacological Reports, vol. 65, no. 2, pp. 288-304, 2013.

[79] S. Cao, G. B. Walker, X. Wang, J. Z. Cui, and J. A. Matsubara, "Altered cytokine profiles of human retinal pigment epithelium: oxidant injury and replicative senescence," Molecular Vision, vol. 19, pp. 718-728, 2013.

[80] X. Cao, D. Shen, M. M. Patel et al., "Macrophage polarization in the maculae of age-related macular degeneration: a pilot study," Pathology International, vol. 61, no. 9, pp. 528-535, 2011.

[81] W. Luo, F. Xie, Z. Zhang, and D. Sun, "Vascular adhesion protein 1 in the eye," Journal of Ophthalmology, vol. 2013, Article ID 925267, 10 pages, 2013.

[82] S. M. Ecker, S. M. Pfahler, J. C. Hines, A. S. Lovelace, and B. M. Glaser, "Sequential in-office vitreous aspirates demonstrate vitreous matrix metalloproteinase 9 levels correlate with the amount of subretinal fluid in eyes with wet age-related macular degeneration," Molecular Vision, vol. 18, pp. 1658-1667, 2012.

[83] J. M. Skeie, S. Zeng, E. A. Faidley, and R. F. Mullins, "Angiogenin in age-related macular degeneration," Molecular Vision, vol. 17, pp. 576-582, 2011.

[84] P. Hahn, Y. Qian, T. Dentchev et al., "Disruption of ceruloplasmin and hephaestin in mice causes retinal iron overload and retinal degeneration with features of age-related macular degeneration," Proceedings of the National Academy of Sciences of the United States of America, vol. 101, no. 38, pp. 13850-13855, 2004 . 
[85] G. Thumann, "Prospectives for gene therapy of retinal degenerations," Current Genomics, vol. 13, no. 5, pp. 350-362, 2012.

[86] L. Feeney-Burns, E. S. Hilderbrand, and S. Eldridge, "Aging human RPE: morphometric analysis of macular, equatorial, and peripheral cells," Investigative Ophthalmology and Visual Science, vol. 25, no. 2, pp. 195-200, 1984.

[87] H. Du, X. Sun, M. Guma et al., "JNK inhibition reduces apoptosis and neovascularization in a murine model of age-related macular degeneration," Proceedings of the National Academy of Sciences of the United States of America, vol. 110, no. 6, pp. 23772382, 2013.

[88] C. M. Ethen, S. A. Hussong, C. Reilly, X. Feng, T. W. Olsen, and D. A. Ferrington, "Transformation of the proteasome with agerelated macular degeneration," FEBS Letters, vol. 581, no. 5, pp. 885-890, 2007.

[89] H. Arai, "Platelet-activating factor acetylhydrolase," Prostaglandins and Other Lipid Mediators, vol. 68-69, pp. 83-94, 2002.

[90] C. A. Demopoulos, R. N. Pinckard, and D. J. Hanahan, "Plateletactivating factor. Evidence for 1-0-alkyl-2-acetyl-sn-glyceryl-3phosphorylcholine as the active component (a new class of lipid chemical mediators)," The Journal of Biological Chemistry, vol. 254, no. 19, pp. 9355-9358, 1979.

[91] W. Chao and M. S. Olson, "Platelet-activating factor: receptors and signal transduction," Biochemical Journal, vol. 292, no. 3, pp. 617-629, 1993.

[92] L. M. McManus and R. N. Pinckard, "PAF, a putative mediator of oral inflammation," Critical Reviews in Oral Biology and Medicine, vol. 11, no. 2, pp. 240-258, 2000.

[93] Z. S. Derewenda and U. Derewenda, "The structure and function of platelet-activating factor acetylhydrolases," Cellular and Molecular Life Sciences, vol. 54, no. 5, pp. 446-455, 1998.

[94] M. Bhatia, "Inflammatory response on the pancreatic acinar cell injury," Scandinavian Journal of Surgery, vol. 94, no. 2, pp. 97102, 2005.

[95] N. A. Sharif, S. Xu, P. E. Hellberg, I. Pang, D. A. Gamache, and J. M. Yanni, "Human conjunctival epithelial cell responses to platelet-activating factor (PAF): signal transduction and release of proinflammatory cytokines," Molecular Vision, vol. 15, pp. 1153-1161, 2009.

[96] N. Okumura, A. Fukushima, A. Igarashi, T. Sumi, T. Yamagishi, and H. Ueno, "Pharmacokinetic analysis of platelet-activating factor in the tears of guinea pigs with allergic conjunctivitis," Journal of Ocular Pharmacology and Therapeutics, vol. 22, no. 5, pp. 347-352, 2006.

[97] J. He and H. E. P. Bazan, "Synergistic effect of platelet-activating factor and tumor necrosis factor-alpha on corneal myofibroblast apoptosis," Investigative Ophthalmology and Visual Science, vol. 47, no. 3, pp. 883-891, 2006.

[98] X. Ma and H. E. P. Bazan, "Increased platelet-activating factor receptor gene expression by corneal epithelial wound healing," Investigative Ophthalmology and Visual Science, vol. 41, no. 7, pp. 1696-1702, 2000.

[99] F. Taheri and H. E. P. Bazan, "Platelet-activating factor overturns the transcriptional repressor disposition of Sp1 in the expression of MMP-9 in human corneal epithelial cells," Investigative Ophthalmology and Visual Science, vol. 48, no. 5, pp. 1931-1941, 2007.

[100] X. Ma, P. Ottino, H. E. P. Bazan, and N. G. Bazan, "Plateletactivating factor (PAF) induces corneal neovascularization and upregulates VEGF expression in endothelial cells," Investigative Ophthalmology and Visual Science, vol. 45, no. 9, pp. 2915-2921, 2004.
[101] J. He, J. P. Eastlack, and H. E. P. Bazan, "The induction of an angiogenic response in corneal myofibroblasts by PlateletActivating Factor (PAF)," Current Eye Research, vol. 35, no. 12, pp. 1063-1071, 2010.

[102] N. G. Bazan, "Lipid signaling in neural plasticity, brain repair, and neuroprotection," Molecular Neurobiology, vol. 32, no. 1, pp. 89-103, 2005.

[103] O. Zinchuk, A. Fukushima, V. Zinchuk, K. Fukata, and H. Ueno, "Direct action of platelet activating factor (PAF) induces eosinophil accumulation and enhances expression of PAF receptors in conjunctivitis," Molecular Vision, vol. 11, pp. 114123, 2005.

[104] D. Smith, E. K. Lee, P. Saloupis, J. K. Davis, and D. L. Hatchell, "Role of neutrophils in breakdown of the blood-retinal barrier following intravitreal injection of platelet-activating factor," Experimental Eye Research, vol. 59, no. 4, pp. 425-432, 1994.

[105] S. Dharma, H. E. P. Bazan, G. A. Peyman, and M. S. E. Atef, "Production of platelet-activating factor in photocoagulated retinas," Current Eye Research, vol. 10, no. 11, pp. 1031-1035, 1991.

[106] J. M. Menerath, J. Cluzel, M. T. Droy-Lefaix, and M. Doly, "Experimental electroretinographic exploration of retinal ischemia: preventive use of free radical scavengers and anti-PAF agents," Journal of Ocular Pharmacology and Therapeutics, vol. 13, no. 1, pp. 81-88, 1997.

[107] Y. G. He, H. Wang, B. Zhao et al., "Functional analysis of platelet-activating factor in the retinal pigment epithelial cells and choroidal endothelial cells," Current Eye Research, vol. 34, no. 11, pp. 957-965, 2009.

[108] M. Al-Latayfeh, P. S. Silva, J. K. Sun, and L. P. Aiello, "Antiangiogenic therapy for ischemic retinopathies," Cold Spring Harbor Perspectives in Medicine, vol. 2, no. 6, Article ID a006411, 2012.

[109] CATT Research Group, D. F. Martin, M. G. Maguire et al., "Ranibizumab and bevacizumab for neovascular age-related macular degeneration," The New England Journal of Medicine, vol. 64, no. 20, pp. 1897-1908, 2011.

[110] U. Chakravarthy, S. P. Harding, C. A. Rogers et al., "Alternative treatments to inhibit VEGF in age-related choroidal neovascularisation: 2-year findings of the IVAN randomised controlled trial," The Lancet, vol. 382, no. 9900, pp. 1258-1267, 2013.

[111] T. R. Friberg, M. Tolentino, P. Weber, S. Patel, S. Campbell, and M. Goldbaum, "Pegaptanib sodium as maintenance therapy in neovascular age-related macular degeneration: the LEVEL study, British Journal of Ophthalmology, vol. 94, no. 12, pp. 16111617, 2010.

[112] J. S. Heier, D. M. Brown, V. Chong et al., "Intravitreal aflibercept (VEGF trap-eye) in wet age related macular degeneration," Ophthalmology, vol. 119, no. 12, pp. 2537-2548, 2012.

[113] J. S. Heier, D. M. Brown, V. Chong et al., "Intravitreal aflibercept (VEGF trap-eye) in wet age related macular degeneration," Ophthalmology, vol. 20, no. 1, pp. 209-210, 2013.

[114] T. Moutray and U. Chakravarthy, "Age-related macular degeneration: current treatment and future options," Therapeutic Advances in Chronic Disease, vol. 2, no. 5, pp. 325-331, 2011.

[115] Y. Chen and F. Han, "Profile of ranibizumab: efficacy and safety for the treatment of wet age-related macular degeneration," Therapeutics and Clinical Risk Management, vol. 8, pp. 343-351, 2012.

[116] H. Ahmadieh, R. Taei, M. Soheilian et al., "Single-session photodynamic therapy combined with intravitreal bevacizumab and triamcinolone for neovascular age-related macular degeneration," BMC Ophthalmology, vol. 7, article 10, 2007. 
[117] Age-Related Eye Disease Study Research Group, "A randomized, placebo-controlled, clinical trial of high-dose supplementation with vitamins $\mathrm{C}$ and $\mathrm{E}$, beta carotene, and zinc for agerelated macular degeneration and vision loss: AREDS report no. 8," Archives of Ophthalmology, vol. 119, no. 10, pp. 1417-1436, 2001, Erratum in Archives of Ophthalmology, vol. 126, no. 9, pp. 1251, 2008.

[118] "The effect of vitamin $\mathrm{E}$ and beta carotene on the incidence of lung cancer and other cancers in male smokers. The AlphaTocopherol, Beta Carotene Cancer Prevention Study Group," The New England Journal of Medicine, vol. 330, no. 15, pp. 10291035, 1994.

[119] G. S. Omenn, G. E. Goodman, M. D. Thornquist et al., "Effects of a combination of beta carotene and vitamin A on lung cancer and cardiovascular disease," The New England Journal of Medicine, vol. 334, no. 18, pp. 1150-1155, 1996.

[120] V. Parisi, M. Tedeschi, G. Gallinaro, M. Varano, S. Saviano, and S. Piermarocchi, "Carotenoids and antioxidants in agerelated maculopathy Italian study: multifocal electroretinogram modifications after 1 year," Ophthalmology, vol. 115, no. 2, pp. 324.e2-333.e2, 2008.

[121] A. García-Layana, S. Recalde, A. S. Alamán, and P. F. Robredo, "Effects of lutein and docosahexaenoic acid supplementation on macular pigment optical density in a randomized controlled trial," Nutrients, vol. 5, no. 2, pp. 543-551, 2013.

[122] W. G. Christen, R. J. Glynn, E. Y. Chew, C. M. Albert, and J. E. Manson, "Folic acid, pyridoxine, and cyanocobalamin combination treatment and age-related macular degeneration in women: the women's antioxidant and folic acid cardiovascular study," Archives of Internal Medicine, vol. 169, no. 4, pp. 335-341, 2009.

[123] M. M. Moschos, I. P. Chatziralli, G. Stamatakis, V. D. Papakonstantinou, and C. A. Demopoulos, "In vitro effects of vitamin supplements on platelet-activating factor and its metabolism in age-related macular degeneration," Cutaneous and Ocular Toxicology, 2013. 

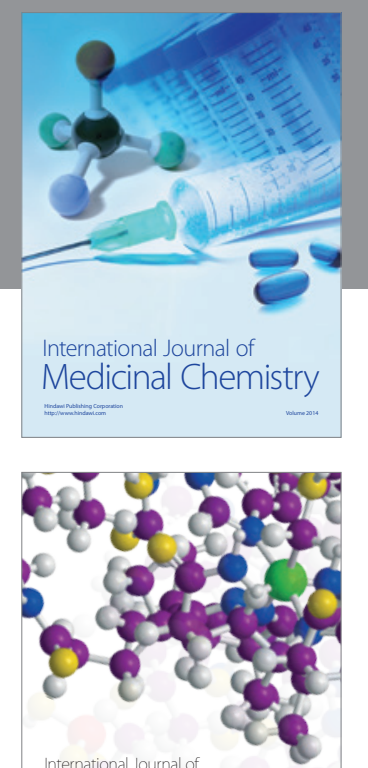

\section{Carbohydrate} Chemistry

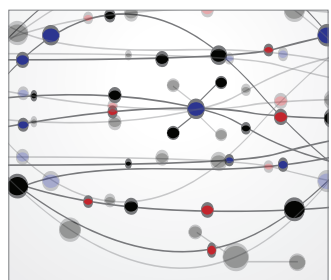

The Scientific World Journal
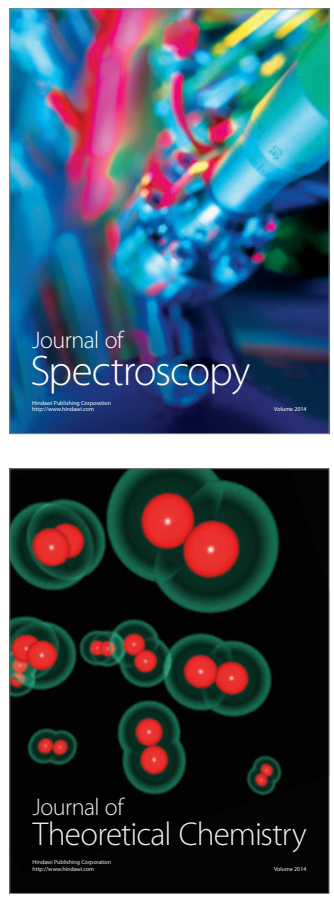
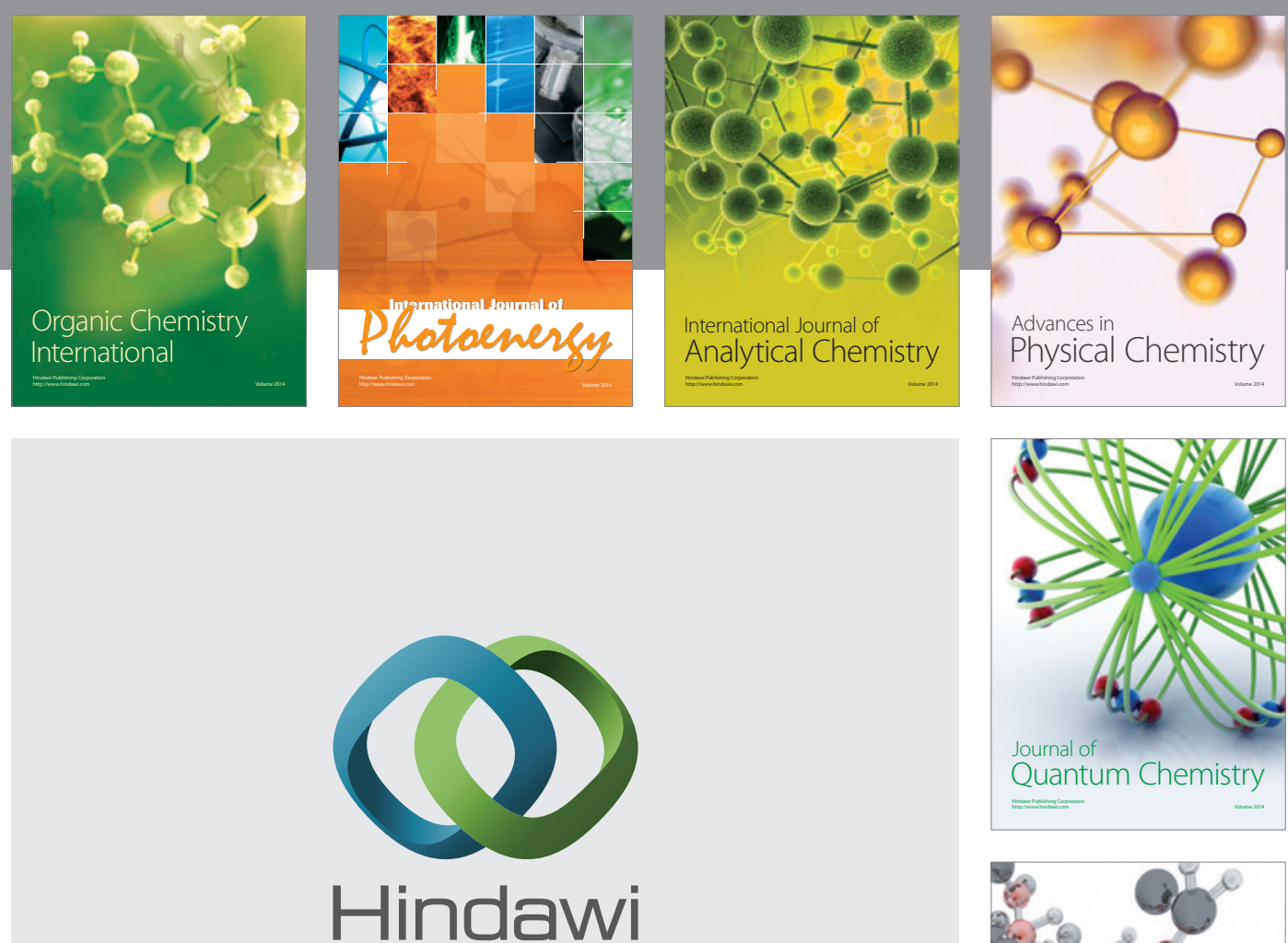

Submit your manuscripts at

http://www.hindawi.com

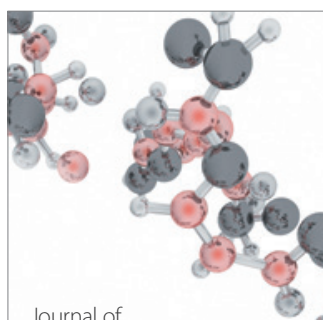

Analytical Methods

in Chemistry

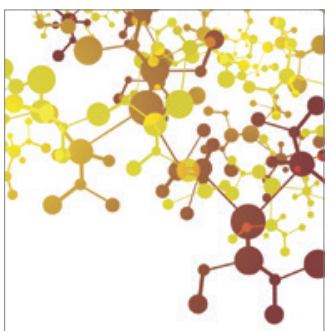

Journal of

Applied Chemistry

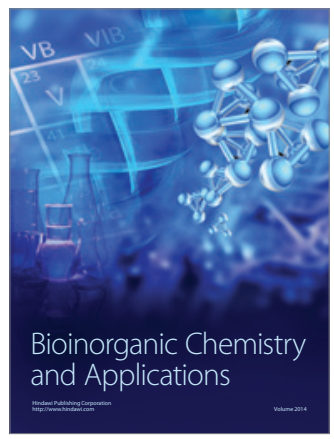

Inorganic Chemistry
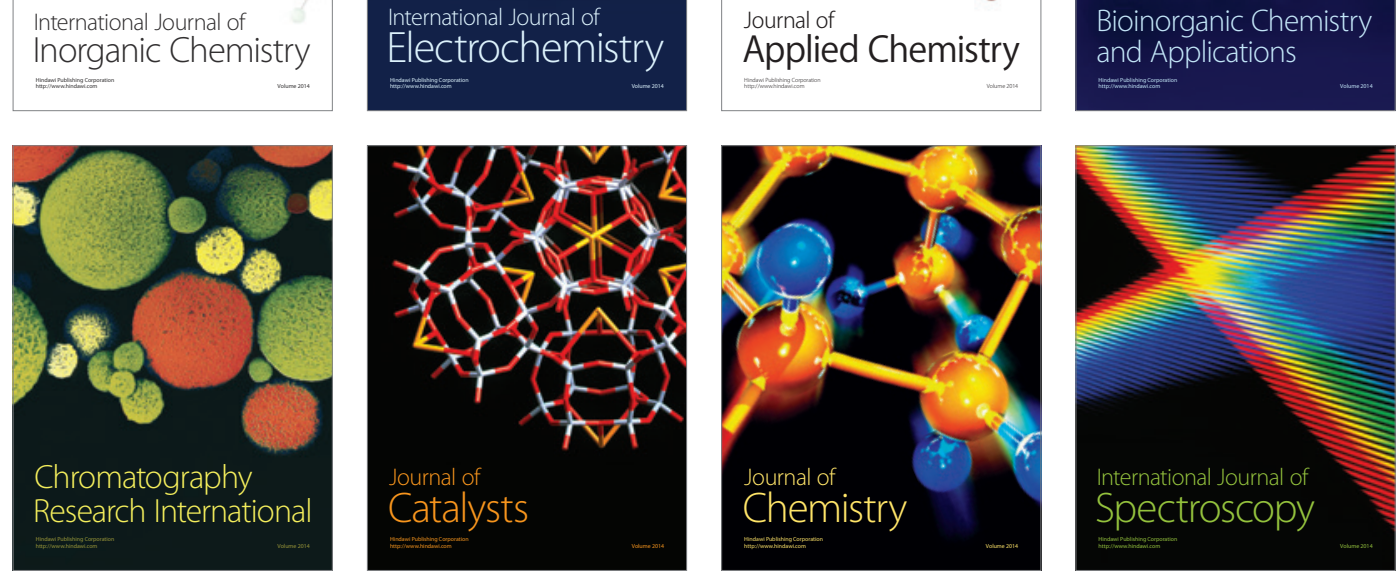